\title{
POLA PRAKTISI BIMBINGAN DAN KONSELING TERHADAP SISWA HOMESCHOOLING DALAM MENGEMBANGKAN POTENSI DIRI
}

\author{
Hajar Ahmad Santoso \\ Universitas Negeri Surabaya, hajarsantoso@mhs.unesa.ac.id \\ Rizqi Mauludiyah \\ Universitas Negeri Surabaya, rizqimauludiyah16010014058@mhs.unesa.ac.id
}

\begin{abstract}
Abstrak
Praktek homeschooling masih menimbulkan berbagai tanggapan kontras pada relevansi dan keefektifannya. Penelitian ini bertujuan untuk memetakan pola hubungan siswa homeschooling dengan pengembangan potensi diri yang telah melalui tahap analisis. Analisis yang dilakukan berfokus pada pemetaan hubungan: a) pengaturan penelitian; b) sampel target; c) metode dan instrumen yang digunakan; d) fokus umum atau masalah yang dibahas; dan e) pola dalam temuan dari perkembangan siswa. Ditemukan bahwa pada penelitian ini lebih fokus dalam mengevaluasi efektivitas dan relevansi homeschooling sebagai alternatif untuk sekolah tradisional, terutama di bidang pengalaman belajar yang efektif dan perkembangan di dunia sosial media. Terlepas dari kelebihan praktik homeschooling, artikel ini juga menemukan keselarasan dari pentingnya bimbingan dan konseling yang dilakukan oleh guru dalam meningkatkan potensi diri siswa. Sehingga penelitian ini memberikan rekomendasi untuk praktik homeschooling yang efektif selanjutnya.
\end{abstract}

Kata Kunci: homeschooling, perkembangan, potensi.

\begin{abstract}
Homeschooling practices still generate a variety of contrasting responses to their relevance and effectiveness. This study aims to map the relationship patterns of homeschooling students with the development of self potential that has been through the analysis phase. The analysis conducted focuses on mapping relationships: a) research arrangements; b) target sample; c) methods and instruments used; d) general focus or issues discussed; and e) patterns in findings from student development. It was found that this study focused more on evaluating the effectiveness and relevance of homeschooling as an alternative to traditional schools, especially in the field of effective learning experiences and developments in the social media world. Apart from the advantages of homeschooling practice, this article also finds harmony from the importance of guidance and counseling conducted by the teacher in improving students' selfpotential. So that this research provides recommendations for further effective homeschooling practices
\end{abstract}

Keywords: homeschooling, development, potential.

\section{PENDAHULUAN}

Hal terpenting pada keberhasilan di dunia pendidikan adalah homeschooling telah menjadi fenomena pendidikan yang berkembang di seluruh dunia. Tampaknya, dalam pengajaran dan pembelajaran homeschooling, input dan hasil akademis dapat diwujudkan orang tua dalam menyesuaikan kebutuhan anak-anak mereka dalam belajar. Sebuah homeschooling yang terstruktur telah terbukti efektif dalam meningkatkan keberhasilan akademik (Cogan, 2010; Harding, 2013; Rudner, 1999). Namun, banyak peneliti memiliki perbedaan pendapat dari fakta yang ada di lapangan. Perkembangan literasi saat ini tampaknya sedang mengalami penurunan pada basis pengetahuan empiris dan akibat pada pembenaran keefektivitasan homeschooling. Murphy (2014) merangkum penelitian secara keseluruhan dari dampak homeschooling, hasil dari penelitian itu masih dinilai kurang dalam penerapan pembelajaran yang sebenarnya.

Jika dilihat dari sekolah secara umumnya, homeschooling merupakan suatu sistem yang memudahkan siswa untuk fokus pada potensi diri yang dimiliki setiap individu. Tentu, terdapat banyak perbedaan pendapat mengenai kelebihan dan kekurangannya.
Hennessy (2014) membandingkan antara sekolah umum dan homeschooling dalam bidang agama. Hasilnya menunjukan bahwa siswa sekolah umum cenderung memiliki tingkat keimanan yang relative tinggi. Hal ini disebabkan bahwa lingkungan disekolah lebih membentuk perubahan rohani yang dialami siswa tersebut. Selain itu, pada Anderson (2014) menyatakan bahwa peningkatan keagamaan pada siswa homeschooling lebih secara stabil meningkat disebabkan oleh peranan seorang ayah dirumah. Pada penelitian itu dijelaskan bahwa kedekatan orang tua menjadi alasan utama dalam menigkatnya perkembangan religious pada siswa tersebut.

Korkmaz \& Duman (2014) menjeskan bahwa explorasi bernalar siswa homeschooling dapat menigkatkan karakter yang lebih baik dan menyediakan gaya belajar yang menyenangkan bagi siswa. Pada artikel itu dijelaskan bahwa keberadaan siswa di sekolah umum menjadi dampak besar dalam perkembangan potensi setiap individu. Ada 5 hal dasar yang mempengaruhi hal itu, yakni 1) karakter siswa yang bermacam - macam; 2) perbedaan agama; 3) rasa percaya diri; 4) pengaturan kurikulum sekolah; dan 5) tipe pembelajaran dan tingkat kekayaan siswa. Hal ini jelas menunjukan adanya 
kelebihan dan kekurungan yang ditimbulkan dalam homeschooling.

Tinjauan dari literature yang berbeda menunjukan bahwa orang tua membuat keputusan berdasarkan keadaan dan kebutuhan anak - anak mereka. Dalam Literatur itu tidak dijelaskan secara rinci mengenai hasil yang ditetapkan untuk masing-masing metode pengajaran. Tetapi literatur tersebut mengungkapkan berbagai persyaratan negara kepada anak-anak yang melakukan homeschooling dan garis besar pembelajaran dalam homeschooling. Literatur tersebut juga menjelaskan alasan mengapa orang tua lebih dominan memutuskan untuk melakukan homeschooling.

Alasan utama orang tua dalam melakukan homeschooling pada anaknya adalah untuk menghindari kegiatan - kegiatan yang tidak efektif seperti yang dilakukan di sekolah tradisional. Fokus yang ada pada pembelajaran homeschooling adalah bagaimana meningkatkan kemampuan siswa sesuai dengan ZPD (Zone Proximate Development) siswa. Pembelajaran yang dilakukanpun dinilai sangat efektif dan menyesuaikan dengan potensi yang dimiliki siswa.

Bimbingan dan konseling yang merupakan modal utama homechooling memiliki pengaruh yang sangat besar. Peran bimbingan dan konseling telah menjadi kurikulum dasar dari homeschooling. Tentu setiap siswa homeschooling memiliki cara yang berbeda dalam belajar, sehingga pada konteks ini memunculkan dampak besar yang ditimbulkan oleh guru bimbingan dan konseling terutama dalam mengembangkan potensi yang ada pada diri siswa.

Menurut Depdiknas (2007:220-223), tersusunnya program layanan bimbingan dan konseling di setiap sekolah yang ada di Indonesia memiliki kegiatan yang diawali dengan kegiatan asesmen, yaitu kegiatan membaca situasi aspek yang dijadikan modal bagi tersusunnya program layanan bimbingan dan konseling. Program inilah yang diadaptasi oleh guru bimbingan dan konseling pada homeschooling. Mengacu pada penilaian yang telah dilakukan pada perangkat administrasi layanan bimbingan dan konseling pada salah satu homeschooling di Indonesia yang dilakukan peneliti, hasilnya adalah penyusunan program layanan bimbingan dan konseling pada homeschooling termasuk dalam needs assessment. Terbentuknya hubungan kolaborasif antar guru pelajar dan guru bimbingan dan konseling menimbulkan hasil yang memuaskan pada siswa, sehingga menimbulkan dampak positif dalam penyelenggaraan pola yang jelas dan terukur.

Struktur pengembangan program bimbingan dan konseling menurut American School Counselor Association (ASCA) sebagai berikut:

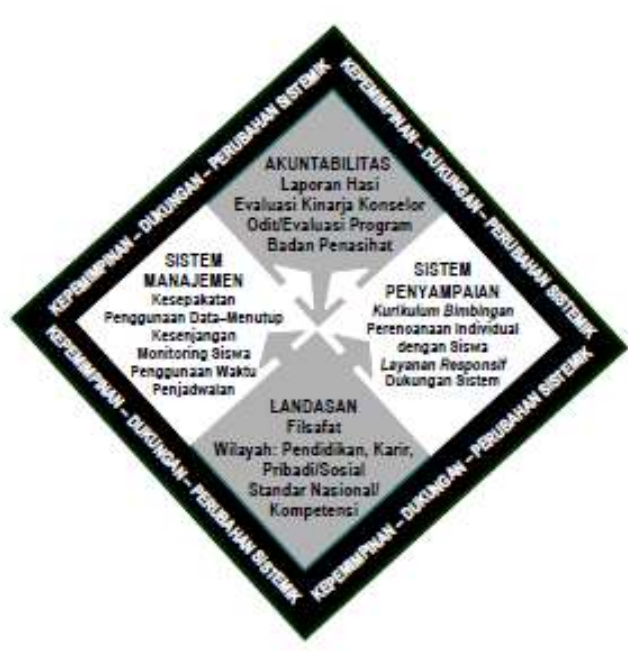

Gambar 1. School Counseling Program Structure (American School Counselor Association, 2005: 20).

Dari hasil pre-research yang telah melalui proses evaluasi, terhadap 8 siswa homeschooling, yang merasakan dampak positif dari hadirnya counselor. Salah satunya adalah guru bimbingan dan konseling dianggap sebagai penyemangat dan sumber motivasi bagi mereka. Mereka menganggap guru bimbingan dan konseling adalah teman sebaya, sehingga memudahkan counseler dalam melaksanakan tugasnya. Pola sikap yang ditimbulkan oleh siswa seperti ini merupakan hasil yang ditimbulkan dari kefektifan layanan di homeschooling.

Berdasarkan uraian di atas, peneliti berasumsi bahwa layanan ini perlu dilakukan analisis untuk menghasilkan pola praktek layanan bimbingan dan konseling yang efektif pada homeschooling. Pada akhir penelitian ini, peneliti berharap akan mendapakan hubungan antara program layanan bimbingan dan konseling efektif dengan pengembangan potensi diri siswa yang layak digunakan sebagai referensi penyelenggaraan layanan bimbingan dan konseling di homeschooling.

\section{METODE}

Penelitian ini merupakan penelitian kualitatif menggunakan metode campuran (mixed method) kualitatif dan kuantitatif. Prosedur penelitian menggunakan prosedur Borg and Gall (2003) sebagai berikut: 1) Potensi dan Masalah, (a) Analisis kebutuhan (needs assessment, (b) Merumuskan Masalah, (c) Studi literatur, (d) Perencanaan., (e) Pengembangan program awal., 2) Pengembangan program, (a) Validasi program, (b) Revisi program (c) FGD (Focus Group Discussion), (d) Program final. Adapun metode untuk mendapatkan data yang diperlukan, yaitu dengan cara pengamatan, angket, wawancara, dan dokumentasi. Sedangkan Teknik analisis data menggunakan teknik analisis deskriptif kualitatif.

\section{HASIL DAN PEMBAHASAN}

Berdasarkan data hasil penelitian dapat disimpulkan secara umum bahwa salah satu homeschooling di Surabaya memiliki program layanan bimbingan dan 
konseling yang baik dengan skor 83,35\%. Hasil penelitian dapat dipaparkan sebagai berikut :

1. Penilaian terhadap hal yang melandasi kegiatan bimbingan dan konseling memiliki nilai rata - rata $75,83 \%$, dengan nilai:

Tabel 1. Penilaian terhadap Landasan

\begin{tabular}{|c|l|c|}
\hline No & \multicolumn{1}{|c|}{ Aspek } & Nilai \\
\hline 1 & Rasionalisasi & 75 \\
\hline 2 & Keselarasan Visi dan Misi & 80 \\
\hline 3 & Ketepatan Deskripsi Kebutuhan & 70 \\
\hline 4 & Kejelasan Deskripsi Kebutuhan & 70 \\
\hline 5 & $\begin{array}{l}\text { Kejelasan tujuan setiap bidang } \\
\text { Pengembangan }\end{array}$ & 70 \\
\hline 6 & $\begin{array}{l}\text { Kesesuaian bidang pengembangan } \\
\text { dengan deskripsi kebutuhan dan } \\
\text { tujuan }\end{array}$ & 90 \\
\hline
\end{tabular}

2. Penilaian terhadap Komponen program layanan bimbingan dan konseling memiliki niali rata-rata $82,50 \%$, dengan nilai:

Tabel 2. Penilaian terhadap Komponen Program

\begin{tabular}{|c|l|c|}
\hline No & \multicolumn{1}{|c|}{ Aspek } & Nilai \\
\hline 1 & Visibilitas Pelayanan Dasar & 70 \\
\hline 2 & Kejelasan Pelayanan Dasar & 80 \\
\hline 3 & Visibilitas Pelayanan Respon & 85 \\
\hline 4 & Kejelasan Pelayanan Respon & 75 \\
\hline 5 & Visibilitas Perencanaan Individual & 85 \\
\hline 6 & Kejelasan Perencanaan Individual & 90 \\
\hline 7 & Visibilitas Dukungan Sistem & 90 \\
\hline 8 & Kejelasan Dukungan Sistem & 85 \\
\hline
\end{tabular}

3. Penilaian terhadap sistem manajemen memiliki nilai rata-rata $86,35 \%$, dengan nilai:

Tabel 3. Penilaian terhadap Sistem Manajemen

\begin{tabular}{|c|c|c|}
\hline No & Aspek & Nilai \\
\hline 1 & $\begin{array}{l}\text { Kejelasan Deskripsi Tugas Personil } \\
\text { Homeschooling }\end{array}$ & 80 \\
\hline 2 & $\begin{array}{ll}\text { Ketepatan Pemilihan } & \text { Dewan } \\
\text { Penasihat } & \end{array}$ & 85 \\
\hline 3 & $\begin{array}{llll}\begin{array}{l}\text { Kejelasan } \\
\text { Digunakan }\end{array} & \text { Data } & \text { Yang } & \text { Akan } \\
\end{array}$ & 90 \\
\hline 4 & $\begin{array}{l}\text { Kesesuaian Alokasi } \quad \text { Waktu } \\
\text { Pelayanan Dasar }\end{array}$ & 85 \\
\hline 5 & $\begin{array}{l}\text { Kesesuaian Alokasi } \\
\text { Pelayanan Responsif }\end{array}$ & 85 \\
\hline 6 & $\begin{array}{l}\text { Kesesuaian Alokasi } \\
\text { Perencanaan Individual }\end{array}$ & 85 \\
\hline 7 & $\begin{array}{l}\text { Kesesuaian Alokasi } \\
\text { Dukungan Sistem }\end{array}$ & 80 \\
\hline 8 & Bentuk Program Tahunan & 90 \\
\hline 9 & $\begin{array}{lll}\text { Kejelasan } & \text { Deskripsi } & \text { Program } \\
\text { Tahunan } & & \\
\end{array}$ & 87.5 \\
\hline 10 & Bentuk Program Bulanan & 90 \\
\hline 11 & $\begin{array}{lll}\text { Kejelasan } & \text { Deskripsi } & \text { Program } \\
\text { Bulanan } & & \\
\end{array}$ & 87.5 \\
\hline 12 & Bentuk Program Harian & 90 \\
\hline 13 & Kejelasan Deskripsi Program Harian & 87.5 \\
\hline
\end{tabular}

4. Penilaian terhadap akuntabilitas memiliki rata-rata nilai $88,75 \%$, dengan nilai:

Tabel 4. Penilaian terhadap Akuntabilitas

\begin{tabular}{|c|l|c|}
\hline No & \multicolumn{1}{|c|}{ Aspek } & Nilai \\
\hline 1 & Kejelasan Rencana Evaluasi & 87.5 \\
\hline 2 & $\begin{array}{l}\text { Kejelasan Prosedur Pelaksanaan } \\
\text { Evaluasi }\end{array}$ & 90 \\
\hline
\end{tabular}

Berdasarkan hasil kalkulasi yang dilakukan, program diatas memperoleh nilai rata-rata penilaian $83.35 \%$ dan berdasarkan kriteria keefektifan, penilaian tersebut termasuk dalam kategori baik atau layak diimplementasikan. Hal ini mengindikasikan bahwa penerapan program bimbingan dan konseling menurut American School Counselor Association (ASCA) dapat diimplementasikan pada praktek homeschooling selanjutnya. Pola praktisi pelayanan homeschooling sebagai berikut.

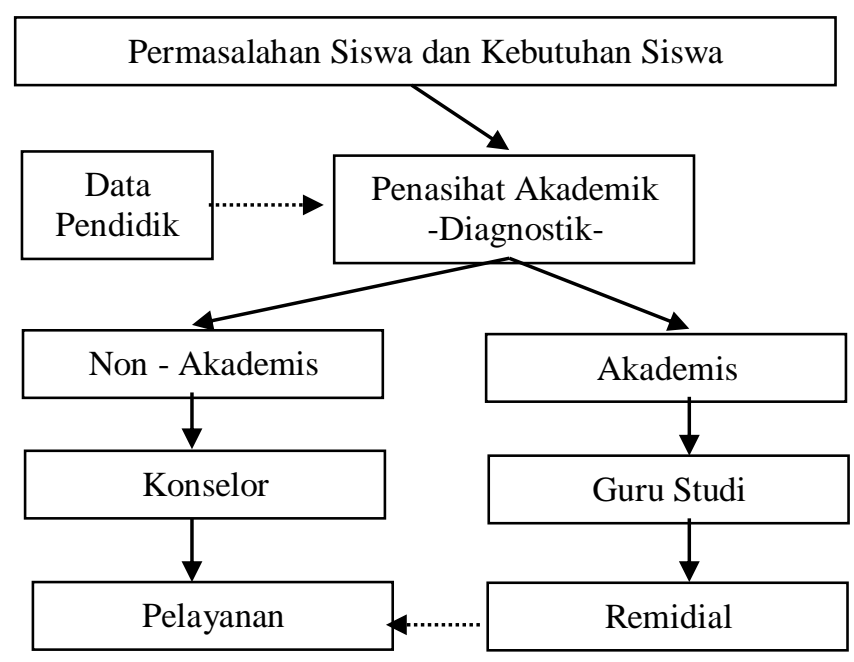

Gambar 2. Pola Praktisi Layanan Bimbingan Konseling

Pola praktisi layanan diatas merupakan penjabaran singkat yang dilakukan peneliti sebagai program layanan yang dapat digunakan sebagai referensi bagi counselor untuk melakukan tugasnya. Pola praktisi diatas juga mempertimbangkan penliaian - penilaian program layanan bimbingan dan konseling yang telah dilakukan. Hal utama yang perlu diperhatikan adalah peran counseler harus disesuaikan dengan keadaan siswa, sehingga membuat siswa lebih nyaman.

Struktur program layanan bimbingan dan konseling yang digunakan adalah sebagai berikut:

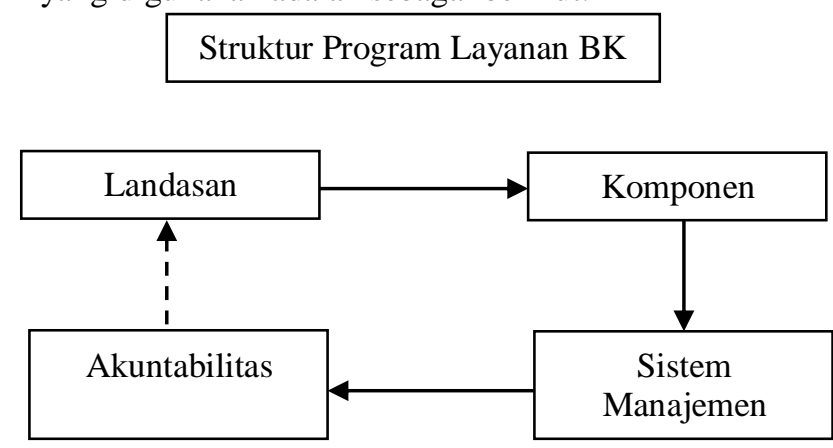

Gambar 3. Pola Praktisi Layanan Bimbingan Konseling 
Namun, Setelah melalui tahap evaluasi, program ini harus disesuaikan dengan kondisi sekolah, terutama dari kualitas guru bimbingan dan konseling. Jika terdapat hasil yang tidak sesuai dalam praktisinya, maka perlu dilakukan evaluasi pada setiap tahapnya, terutama pada sistem manajemen.

\section{PENUTUP}

\section{Simpulan}

Setelah dilakukan tahap analisis dan pembahasan melalui data yang diperoleh, hasilnya adalah program layanan pola praktisi bimbingan dan konseling untuk meningkatkan potensi diri siswa dinyatakan layak diimplementasikan dan termasuk dalam kategori baik Proses pembentukan program layanan bimbingan dan konseling dilakukan menggunakan metode campuran (mixed method) kualitatif dan kuantitatif. Teknik analisis data yang digunakan adalah analisis data deskriptif kualitatif..

\section{Saran}

Berdasarkan hasil dan pembahasan serta kesimpulan yang telah didapat, peneliti menyarankan Bagi : (1) Kepala lembaga Pendidikan untuk mengadakan pertemuan intensif dalam pelayanan konseling kepada siswa untuk selalui mengevaluasi program yang dimiliki; (2) Bagi Guru counselor untuk selalu meningkatkan kualitas konseling dan beradaptasi dengan kondisi siswa agar dapat memotivasi dan mampu mengembangkan potensi diri siswa untuk menjadi lebih baik lagi. Selain itu, untuk saling menjaga hubungan baik kepada guru studi agar tercipta keharmonisan dalam bekerja; (3) Orang tua dan guru studi untuk selalu mengawal program layanan bimbingan dan konseling bagi kebaikan peserta didik.

\section{DAFTAR PUSTAKA}

American School Counselor Association. 2005. The ASCA National Model: A Framework For School Counseling Programs. Second Edition. Alexandria, VA: Author.

Cobia, D. C., \& Henderson, D. A. 2009. Developing An Effective and Accountable School Counseling Program. Second Edition. Upper Saddle River, New
Jersey, Columbus, Ohio: Pearson Merrill Prentice Hall.

Cogan, M. (2010). Exploring academic outcomes of homeschooled students. Journal of College Admission, 208. pp.19-25.

Departemen Pendidikan Nasional. 2007. Penataan Pendidikan Profesional Konselor dan Layanan Bimbingan Konseling dalam Jalur Pendidikan Formal. Jakarta: Direktorat Jenderal Pendidikan Tinggi.

Green-Hennessy, S. (2014). Homeschooled adolescents in the United States: Developmental outcomes. Journal of Adolescence, 37, pp.441-449.

Harding, T. A. (2003). A submission for the Home Schooling Review. Brisbane: Australian Christian Academy.

Korkmaz, H., \& Duman, G. (2014). Public understanding about homeschooling: A preliminary study. Procedia -Social and Behavioral Sciences, 116, pp.3891 3897.

Malott, Krista M.; Paone, Tina R.; Humphreys, Kourtney; Martinez, Triana . (2010).Featured Research. Professional School Counseling.

Murphy, J. (2014). The social and educational outcomes of homeschooling. Sociological Spectrum, 34, pp.244-272.

Ray, B. D. (2002). Customization through homeschooling. Educational Leadership, 59/7/, pp.50-54.

Rudner, L. M. (1999). Scholastic achievement and demographic characteristics of home school students in 1998. Educational Policy Analysis Archives, 7(8), pp.1068-2341.

Syamsu Yusuf \& A Juntika Nurihsan. 2003. Penyusunan Program Bimbingan dan Konseling Berbasis Perkembangan. Panduan Workshop Bimbingan dan Konseling dalam Acara Konvensi Nasi-onal XIII Asosiasi Bimbingan.

Wilhelm, G., \& Firman, M. (2009). Historical and contemporary development in home school education. Journal of Research on Christian Education, 18, pp.303-315. 